\section{Treating osteoporosis: concerns about calcium}

Aust Prescr 2016;39:150

http://dx.doi.org/10.18773/austprescr.2016.073

I enjoyed reading the recent article by Akhil Gupta and Lyn March on the treatment of osteoporosis.'

I especially appreciated the inclusion of the numbers needed to treat (NNTs) with antiresorptive drugs to prevent a fracture. Such measures of absolute benefit are helpful for shared decision-making with our patients. However, I was disappointed that the same care was not taken in the discussion of calcium supplementation. Here, the authors simply stated that 'combined calcium and vitamin D supplements seem safe and effective for most people who require them:

I agree with the authors' concerns that the cardiovascular safety of calcium supplementation are unresolved. ${ }^{2,3}$ In this context of possible harm, I believe we need to carefully consider the purported benefits of calcium. A systematic review found that calcium supplementation has little if any effect in reducing fracture. ${ }^{4}$ There was an overall 11\% (95\% Cl* 4-19\%) relative risk reduction in total fracture, which became smaller and statistically insignificant when the authors restricted their analysis to trials at low risk of bias (4\%, 95\% Cl -1 to 9\%). For the typical person with osteoporosis, these figures will equate to large NNTs for fracture prevention - much larger than those for antiresorptive drugs - if indeed there is any real benefit at all. I struggle to see then how calcium supplementation can be deemed 'effective for most people' as claimed.

\section{Brett Montgomery}

Senior lecturer, General Practice

School of Primary, Aboriginal and Rural Health

Care

University of Western Australia

Crawley

\section{REFERENCES}

1. Gupta A, March L. Treating osteoporosis. Aust Prescr 2016;39:40-6. http://dx.doi.org/10.18773/ austprescr.2016.028

2. Bolland MJ, Grey A, Avenell A, Gamble GD, Reid IR. Calcium supplements with or without vitamin D and risk of cardiovascular events: reanalysis of the Women's Health Initiative limited access dataset and meta-analysis. BMJ 2011;342:d2040. http://dx.doi.org/10.1136/bmj.d2040

3. Lewis JR, Radavelli-Bagatini S, Rejnmark L, Chen JS, Simpson JM, Lappe JM, et al. The effects of calcium supplementation on verified coronary heart disease hospitalization and death in postmenopausal women: a collaborative meta-analysis of randomized controlled trials. J Bone Miner Res 2015;30:165-75. http://dx.doi.org/ 10.1002/jbmr.2311

4. Bolland MJ, Leung W, Tai V, Bastin S, Gamble GD, Grey A et al. Calcium intake and risk of fracture: systematic review. BMJ 2015:351:h4580. http://dx.doi.org/10.1136/bmi.h4580

* confidence interval

Lyn March and Akhil Gupta, the authors of the article, comment:

Thank you for your comments on our recent article. You make some important points about the weak effect of calcium alone for fracture prevention. We did not include calcium and vitamin $D$ in the tables of numbers needed to treat as we did not feel they were sufficiently effective on their own or in combination, but rather as part of the whole treatment package when antiresorptives are being prescribed.

The benefits and harms of calcium supplements for osteoporosis remain controversial. We state in the article that 'it is recommended that people get this through their diet' but also suggest that 'most Australians do not reach the recommended dietary intake so daily supplements of 500-600 mg of calcium are sometimes needed'. There are insufficient data from randomised trials to offer the same level of certainty about numbers needed to harm for calcium. In the context of 'safe and effective' we were referring to it as a mode for achieving the recommended daily calcium requirement, not as it being an effective drug for reducing fractures. It would have been better if we had omitted 'and effective' as it could be misleading. 